\title{
Usefulness of Ultrahigh Resolution Microstructural Studies for Understanding Localized Corrosion Behavior of Al Alloys
}

\author{
M. Kappes, ${ }^{a}$ L. Kovarik, ${ }^{a}$ M. J. Mills, ${ }^{a}$ G. S. Frankel, ${ }^{\mathrm{a}, *, \mathrm{z}}$ and M. K. Miller ${ }^{\mathrm{b}}$ \\ ${ }^{a}$ Department of Materials Science and Engineering, The Ohio State University, Columbus, \\ Ohio 43210, USA \\ ${ }^{b}$ Materials Science and Technology Division, Oak Ridge National Laboratories, Oak Ridge, \\ Tennessee 37831-6136, USA
}

\begin{abstract}
The corrosion behavior of different tempers of two aluminum alloys, AA7050 and an experimental Al-Mg-Cu-Si alloy, was studied in $\mathrm{NaCl}$ solution by anodic polarization and scanning electron microscopy and was correlated with differences in the microstructure. Potentiodynamic polarization experiments were performed on samples from the exact sheets used by others to study the microstructure evolution during the early stages of the precipitation sequence by high-resolution characterization tools [i.e., high-resolution transmission electron microscopy and atom probe tomography (APT)]. The usefulness of information from these state-of-the-art tools to lead to a better understanding about the effects of nanoscale segregation on localized corrosion of aluminum alloys is discussed. APT was able to provide information about the composition of the solid solution matrix region between the fine-scale hardening particles, which is not possible by any other technique. Some of the changes in corrosion behavior, e.g., the breakdown potentials, with temper could be rationalized based on changes in the matrix composition. The formation of corrosion-susceptible surface layers on as-polished AA7050 depended on the predominant type of hardening particle. The lack of detailed knowledge of the grain boundary region limited the applicability of the microstructural information generated by previous studies for understanding intergranular corrosion.
\end{abstract}

(C) 2008 The Electrochemical Society. [DOI: 10.1149/1.2939212] All rights reserved.

Manuscript submitted January 24, 2008; revised manuscript received May 12, 2008. Available electronically June 18, 2008.

Wrought precipitation-hardenable aluminum alloys are used extensively in structural applications due to their high strength/density ratio. ${ }^{1}$ Their heat-treatment normally involves a solution treatment at high temperature to dissolve the alloying elements, rapid cooling, or quenching to obtain a supersaturated solid solution (SSSS) of the alloying elements in the aluminum matrix, and controlled decomposition of the SSSS to form finely dispersed precipitates. The elements commonly added to $\mathrm{Al}$ for age-hardening response are $\mathrm{Cu}$, $\mathrm{Mg}, \mathrm{Si}, \mathrm{Li}$, and $\mathrm{Zn}$. Age-hardenable aluminum alloys also have minor amounts of $\mathrm{Fe}, \mathrm{Mn}, \mathrm{Zr}, \mathrm{Cr}$, and $\mathrm{Ti}$ (added deliberately or not). This complex chemical composition results in the presence of three types of second phases: coarse intermetallic compounds or constituent particles $(1-30 \mu \mathrm{m})$, dispersoids $(0.05-0.5 \mu \mathrm{m})$, and fine precipitates $(<0.01 \mu \mathrm{m}){ }^{1,2}$

Whereas the effect of coarse precipitates on corrosion behavior has been studied in detail, ${ }^{3-8}$ the influence of fine-scale $(<0.01 \mu \mathrm{m})$ hardening precipitates, especially those formed during the early stages of the precipitation sequence, on the corrosion properties is not well understood. These particles have the greatest effect on mechanical properties, but their presence and metallurgical characteristics can only be assessed with advanced techniques owing to their extremely small size. They appear within grains according to a complex precipitation sequence of metastable phases during aging treatments, but equilibrium precipitates can be formed readily on grain boundaries. A precipitate-free zone (PFZ) with composition varying considerably from that of the grain interior can be formed near the grain boundary. ${ }^{1,2}$ The presence of particles and segregated elements at the grain boundaries and the neighboring PFZ often makes the grain boundary region in $\mathrm{Al}$ alloys susceptible to intergranular corrosion (IGC). However, metallurgists often focus their studies on the microstructure in the interior of the grains because precipitates appearing therein are the ones that provide increased mechanical strength.

The goal of this work was to characterize the corrosion behavior of alloys for which the microstructure evolution during the early stages of the precipitation sequence has been studied using advanced techniques. A commercial AA7050 alloy and an Al-Mg-Cu-Si experimental alloy were used for this purpose. The samples for corrosion testing were extracted from exactly the same sheets as those

* Electrochemical Society Fellow.

z E-mail: frankel.10@osu.edu used in the characterization studies, and identical thermal treatments were applied. Therefore, the different microstructures for the various aged samples could be used to understand differences in the corrosion behavior. The microstructure studies focused on the grain interiors, with no attention paid to the grain boundary regions. Therefore, the insight provided can only be applied to corrosion phenomena within the grains and not at the grain boundaries.

The generally accepted precipitation sequence for $\mathrm{Al}-\mathrm{Zn}$ $\mathrm{Mg}-\mathrm{Cu}$ alloys, such as AA7050, is $\alpha$ (SSSS) $\rightarrow$ Guinier Preston zones $(\mathrm{GPZs}) \rightarrow \eta^{\prime} \rightarrow \eta^{1,2,9}$ The $\eta$ phase is hexagonal with a nominal stoichiometry given by $\mathrm{MgZn}_{2}$, but copper and aluminum atoms can substitute for zinc; thus, this phase is often designated as $\mathrm{Mg}(\mathrm{Zn}, \mathrm{Cu}, \mathrm{Al})_{2}$. GPZs in these alloys can be divided into GPI and GPII; the main difference arising from the crystallographic planes in the aluminum matrix along which these coherent zones appear. ${ }^{9}$

The evolution of the AA7050 alloy microstructure during artificial aging at $121^{\circ} \mathrm{C}$ was studied recently by Sha and Cerezo using transmission electron microscopy (TEM) and atom probe tomography (APT) using a 3-dimensional atom probe (3DAP). ${ }^{9}$ After a short aging time of $30 \mathrm{~min}$, the microstructure contained Mg-rich GPI zones that nucleated homogeneously and uniformly from the SSSS. GPI zones were dominant up to $60 \mathrm{~min}$ at $121^{\circ} \mathrm{C}$, but were still present after aging for $1440 \mathrm{~min}$. Zn-rich $\eta^{\prime}$ platelets formed after aging between 30 and $240 \mathrm{~min}$ at $121^{\circ} \mathrm{C}$, and increased in volume fraction after longer aging times (Fig. 1a). It was proposed that the $\eta^{\prime}$ formation proceeded by the growth of small GPI zones to form elongated clusters and then by the further growth of these elongated clusters to form platelet $\eta^{\prime} .9$ Larger GPI zones are relatively stable and can continue growing. The concentration of the alloying elements in the matrix $(\mathrm{Zn}, \mathrm{Mg}$, and $\mathrm{Cu})$, determined by 3DAP, decreased with aging time as a result of the segregation of alloying elements in the precipitates (Fig. 1b). ${ }^{9}$ The $\mathrm{Mg}$ and $\mathrm{Cu}$ content of the matrix stabilized after a few hours at $121{ }^{\circ} \mathrm{C}$, whereas the $\mathrm{Zn}$ content was still decreasing after $8 \mathrm{~h}$.

The precipitation sequence of $\mathrm{Al}-\mathrm{Mg}-\mathrm{Cu}$ alloys is considered to be: $\alpha$ (SSSS) $\rightarrow$ GP or Guinier Preston Bagaryatskii (GPB) zones $\rightarrow$ (GPBII) zones $\rightarrow S^{\prime \prime} \rightarrow\left(S^{\prime}\right) S$, in which the $S$ phase is orthorhombic with a stoichiometry given by $\mathrm{Al}_{2} \mathrm{CuMg}$, and $S^{\prime \prime}$ and $S^{\prime}$ are intermediate precipitates of the equilibrium phase. ${ }^{1,10}$ The precipitation evolution of an experimental low $\mathrm{Cu}: \mathrm{Mg}$ ratio alloy of this system, namely $\mathrm{Al}-2.96 \mathrm{Mg}-0.42 \mathrm{Cu}-0.12 \mathrm{Si}$ (in weight percent) recently has been studied by Kovarik et al. by TEM and highresolution transmission electron microscopy (HRTEM) ${ }^{10}$ and APT 


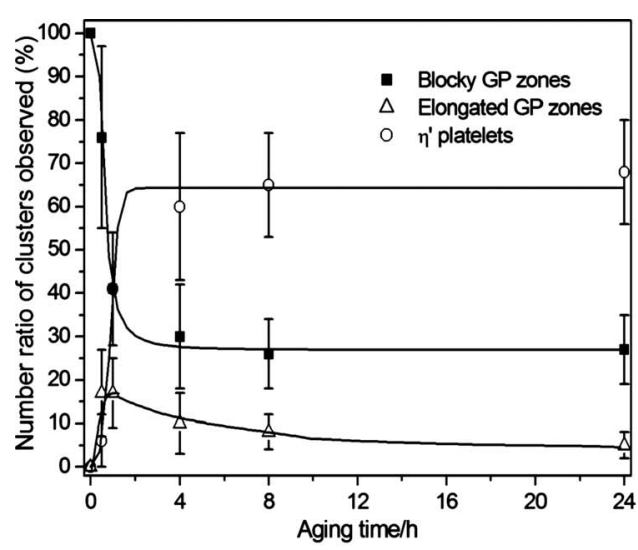

(a)

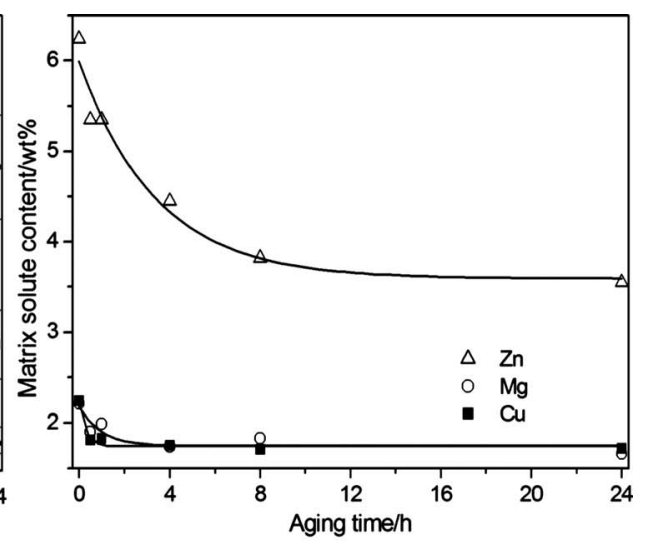

(b)
Figure 1. Evolution of the microstructure of AA7050 during aging at $121^{\circ} \mathrm{C}$ : (a) number ratio of different types of clusters and (b) matrix composition (data taken from Sha and Cerezo ${ }^{9}$ ). using a local electrode atom probe (LEAP). ${ }^{11}$ The magnesium content of this alloy is similar to that found in some of the non-heattreatable alloys of the AA5xxx series. However, the copper content is much higher than that expected for this system and is similar to the copper content found in some of the heat treatable AA6xxx series. The resultant alloy has medium strength, responds to aging treatments, and can maintain work-hardening strength after paint bake, which makes it a suitable choice for car body applications. ${ }^{11}$

When aged at $180^{\circ} \mathrm{C}, \mathrm{GPB}$ zones were observed after $1 \mathrm{~h} .{ }^{10,11}$ After longer aging times at $180^{\circ} \mathrm{C}, 4$ or $8 \mathrm{~h}, \mathrm{GPB}-\mathrm{II}$ zones are also detected. ${ }^{\circ 0}$ After $8 \mathrm{~h}$ aging at $180^{\circ} \mathrm{C}$, it is possible to observe these particles by conventional bright-field TEM imaging, but smaller blocky GPB zones are also present. ${ }^{10,11}$ At this stage of the artificial aging treatment, only about $5.1 \%$ of the $\mathrm{Cu}$ atoms and $12.6 \%$ of the $\mathrm{Si}$ atoms are clustered, with an overall cluster density of 1.1 $\times 10^{23} \mathrm{~m}^{-3} \cdot 11$ No $S$ phase was detected after aging times up to $48 \mathrm{~h}$ at $180^{\circ} \mathrm{C}$ in the matrix, although it could readily precipitate during aging at $200^{\circ} \mathrm{C} .^{12}$

Using a different approach than Sha and Cerezo to present data collected with the atom probe, Kovarik et al. found that 97.7 and 94.9\% of the $\mathrm{Cu}$ content in the 1 and $8 \mathrm{~h}$ samples, respectively, existed in solid solution, including the random clusters. In addition to the microstructural information about this alloy presented in the cited papers, additional analysis has been performed and is summarized herein.

The capabilities of APT allow the determination of the composition of the solid solution matrix phase existing between the very fine hardening particles in precipitation-hardened alloys. This is not possible by any other technique, including analytical TEM, owing to the extremely fine distribution of the hardening particles in most alloys. ${ }^{13}$ Knowledge of the matrix phase composition can allow for a better understanding of the alloy corrosion properties as well as other properties that are dependent on the matrix phase, such as conductivity. This study was undertaken to investigate the usefulness of the information provided by APT and HRTEM for understanding the localized corrosion behavior of two $\mathrm{Al}$ alloys.

\section{Experimental}

The samples for corrosion testing were taken from the same sheets used in the prior studies and were provided by the authors of those studies. The alloys were AA7050 $(6.29 \mathrm{Zn}-2.22 \mathrm{Mg}-2.28 \mathrm{Cu}-$ $0.05 \mathrm{Si}-0.09 \mathrm{Fe}-0.11 \mathrm{Zr}$ in weight percent $)^{9}$ and an experimental $\mathrm{Al}-$ $\mathrm{Mg}-\mathrm{Cu}-\mathrm{Si}$ alloy $(2.96 \mathrm{Mg}-0.42 \mathrm{Cu}-0.12 \mathrm{Si}-0.25 \mathrm{Mn}-0.21 \mathrm{Fe}-$ $0.007 \mathrm{Zn}-0.002 \mathrm{Ti}$ in weight percent). ${ }^{10}$ The heat-treatments applied were identical to those used in the prior studies ${ }^{9-11,14}$ so the corrosion tests could be performed on samples with a microstructure characterized in detail at the nanometer level. The composition of the matrix surrounding the clusters in the $\mathrm{Al}-\mathrm{Mg}-\mathrm{Cu}-\mathrm{Si}$ alloy was measured from selected volumes defined with the aid of atom maps of samples aged for 1 or $8 \mathrm{~h}$, as described below.
Coupons of AA7050 were solution heat-treated for $1.5 \mathrm{~h}$ at $477^{\circ} \mathrm{C}$ in a furnace, quenched in water at room temperature, and aged in an oil bath at $121^{\circ} \mathrm{C}$ immediately after quenching for times up to $48 \mathrm{~h}$. Samples of the $\mathrm{Al}-\mathrm{Mg}-\mathrm{Cu}-\mathrm{Si}$ alloy were solution heattreated for $0.5 \mathrm{~h}$ at $550^{\circ} \mathrm{C}$ in a salt bath, quenched in water at room temperature, and aged in an oil bath at $180^{\circ} \mathrm{C}$ for times up to $24 \mathrm{~h}$. Corrosion testing of both alloys was performed on samples aged the same amount of time as reported in the previous studies. ${ }^{9-11,14}$

The effect of artificial aging on the mechanical properties of both alloys was determined using microhardness measurements with a Vickers hardness indentor on the rolled surface of the coupons. Samples were prepared for these measurements with more aging times than for corrosion testing to obtain a smoother aging response curve. A $200 \mathrm{~g}$ load and a hold time of $20 \mathrm{~s}$ were used for the $\mathrm{Al}-\mathrm{Mg}-\mathrm{Cu}-\mathrm{Si}$ alloy. A higher load of $500 \mathrm{~g}$ was used for the AA7050 alloy because of its expected higher strength.

The samples were encapsulated in ambient-cured epoxy resin to expose one of the rolled surfaces, mechanically ground with successively finer silicon carbide $(\mathrm{SiC})$ paper through 4000 grit in ethanol, and polished with $1 \mu \mathrm{m}$ diamond paste. No water was used during polishing to minimize corrosion. The boundary between the metallic sample and the epoxy resin was masked with acetone-soluble lacquer to minimize the initiation of crevice corrosion in this zone. The metallic surfaces were degreased with ethanol prior to the electrochemical measurements.

The anodic potentiodynamic polarization curves of the differently aged samples were measured at least three times for each metallurgical state. The potential was measured against a saturated calomel electrode (SCE) through a Luggin capillary, and a Pt counter electrode was used. The experiments were carried out in Ar-deareated $0.5 \mathrm{M} \mathrm{NaCl}$, prepared with reagent-grade chemicals and deionized water. The sample was held at open-circuit potential for $15 \mathrm{~min}$ and was then potentiodynamically polarized from $20 \mathrm{mV}$ below the corrosion potential to a potential above the breakdown potential. A scan rate of $0.3 \mathrm{mV} \mathrm{s}^{-1}$ was used for the $\mathrm{Al}-\mathrm{Mg}-\mathrm{Cu}-\mathrm{Si}$ alloy, whereas for the AA7050 alloy a slightly slower rate $\left(0.2 \mathrm{mV} \mathrm{s}^{-1}\right)$ was selected to allow comparison of the curves obtained in this work to those presented in the literature. ${ }^{15}$

Recent results have found that artificially aged 7xxx series aluminum alloys develop a thin active surface layer as a result of plastic deformation introduced during working, machining, or polishing. ${ }^{13,16-18}$ Given this, some of the as-polished samples were ion milled to remove this surface layer, thus allowing for the study of the underlying bulk alloy. The specimen was rotated continuously during the treatment at a few revolutions per minute to minimize the creation of surface grooves ${ }^{19}$ and was cooled with liquid nitrogen to minimize precipitation. However, even though aluminum samples exhibit high thermal conductivity, the creation of vacancies from ion-milling damage could alter diffusivity and, thus, the metallurgical structure. 


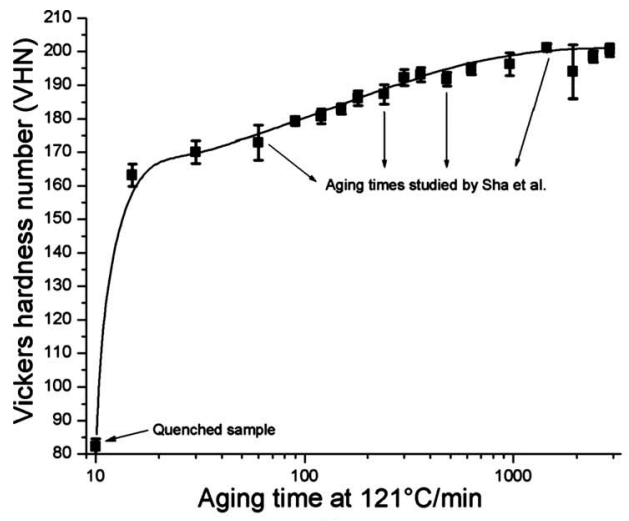

(a)

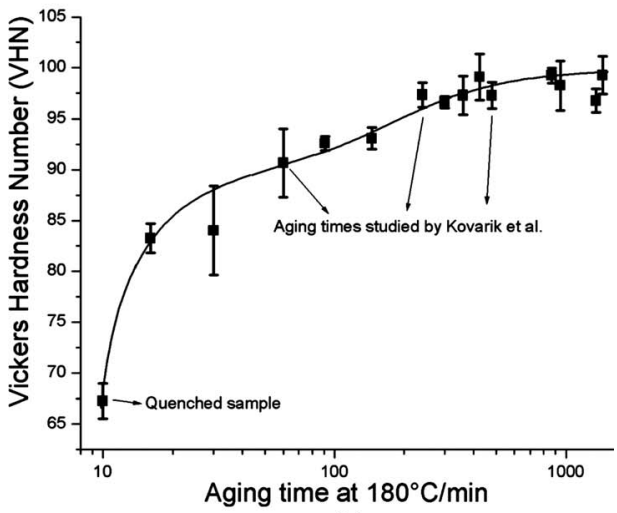

(b)
Figure 2. Hardness evolution of the alloys studied during artificial aging: (a) AA7050 and (b) Al-Mg-Cu-Si alloy. The arrows point out the hardness values at the aging times studied by Sha et al. ${ }^{9,14}$ and Kovarik et al. ${ }^{10,11}$
The attack morphology of samples polarized to a final current of $\sim 1.5 \mathrm{~mA} \mathrm{~cm}^{-2}$ was studied by scanning electron microscopy (SEM) in a FEI Quanta 200 SEM in high-vacuum mode. Samples were ultrasonically cleaned in acetone and ethanol prior to SEM observations.

The ATP experiments on the $\mathrm{Al}-\mathrm{Mg}-\mathrm{Cu}-\mathrm{Si}$ alloy were conducted on a voltage-pulsed LEAP from Imago Scientific Instruments operated with a specimen temperature of $\sim 23 \mathrm{~K}$, a pulse ratio of 0.2 , and a pulse repetition rate of $200 \mathrm{kHz}$. Peak deconvolution methods and background noise subtraction were used for all concentration estimates.

\section{Results}

Hardening response.- The evolution in hardness as a function of aging time for the alloys studied is shown in Fig. 2. The plotted points and the error bars represent the average and standard devia-

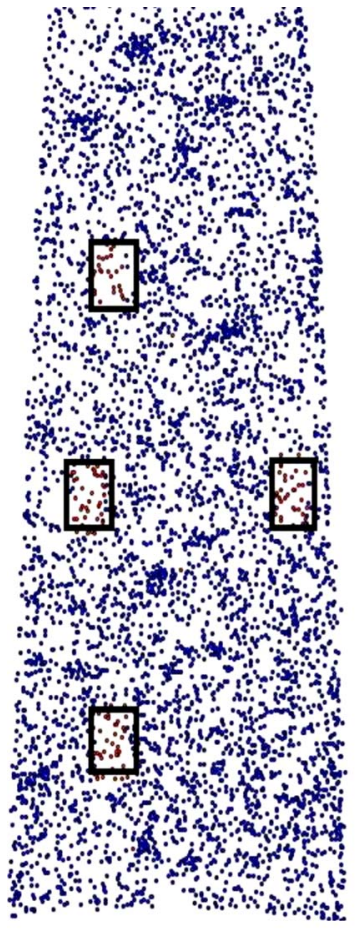

(a)

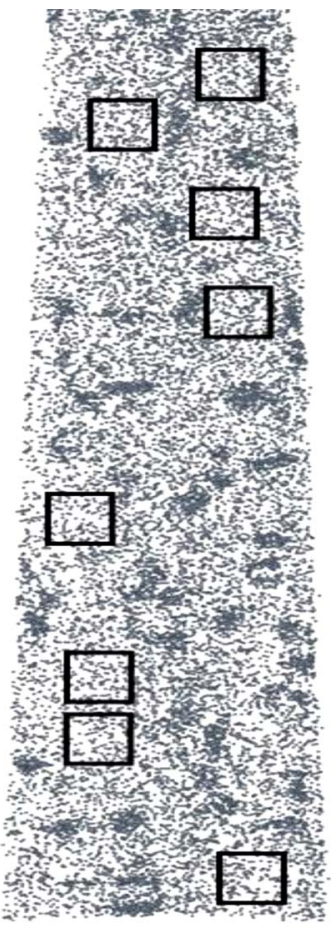

(b)
Figure 3. (Color online) Atom maps depicting the Si distribution in $\mathrm{Al}-\mathrm{Mg}-$ $\mathrm{Cu}-\mathrm{Si}$ samples aged at $180^{\circ} \mathrm{C}$ for (a) 1 and (b) $8 \mathrm{~h}$. The overall dimensions of the reconstructed volumes are $100 \times 250 \times 10 \mathrm{~nm}(1 \mathrm{~h})$ and 80 $\times 300 \times 20 \mathrm{~nm}(8 \mathrm{~h})$. The boxed areas represent the cluster-free zones from which the matrix composition was estimated. tion of 5 hardness measurements, respectively. A rapid-hardening stage was observed in both cases, followed by a stage of lower hardening rate.

For the AA7050 alloy, the supersaturated solid solution was unstable even at room temperature, as the hardness of a sample increased from $\sim 80$ Vickers hardness number (VHN) immediately after quenching to $\sim 145 \mathrm{VHN}$ after natural aging for one week. Similar behavior has been reported in the literature and can be explained in terms of the formation of GPZs. ${ }^{2}$ For this alloy, in particular, nucleation of GPI zones was detected after aging times as low as $1.5 \mathrm{~h}$ at room temperature. ${ }^{9}$ The aging response of the Al$\mathrm{Mg}-\mathrm{Cu}-\mathrm{Si}$ alloy has a similar form as the AA7050, but the hardness is much lower. Alloys of this family do not exhibit room temperature natural aging, ${ }^{20}$ and it was not evident for this alloy.

Matrix composition of the $\mathrm{Al}-\mathrm{Mg}-\mathrm{Cu}-\mathrm{Si}$ alloy.- The matrix composition of the Al-Mg-Cu-Si alloy aged for 1 or $8 \mathrm{~h}$ was determined by analyzing volumes that were collected previously by APT. ${ }^{11}$ For the $1 \mathrm{~h}$ aged sample, two $100 \times 250 \times 10 \mathrm{~nm}$ volumes were used, whereas one $80 \times 300 \times 20 \mathrm{~nm}$ volume was used for the $8 \mathrm{~h}$ sample. A reconstructed $\mathrm{Si}$ atom map for the $1 \mathrm{~h}$ aged sample and the Si atom map for the $8 \mathrm{~h}$ sample are presented in Fig. 3 . These atom maps represent the solute distribution in the artificially aged microstructures. Only the $\mathrm{Si}$ atoms are rendered because the Si distribution provides the highest contrast between matrix and precipitates. The characteristic features of the microstructure are small clusters homogeneously distributed in the matrix. Regions highlighted with a box are zones apparently free of clusters where the matrix composition was measured.

The estimated concentrations of $\mathrm{Mg}, \mathrm{Cu}$, and $\mathrm{Si}$ in the entire reconstructed volume of the sample that was aged for $1 \mathrm{~h}$, along with the concentrations in the matrix (boxed zones in Fig. 3a) and the nominal composition in the alloy are presented in Table I. The concentration was determined from the mass-to-charge-state spectra by evaluating the integral intensity of the peaks.

An example of a mass-to-charge-state spectrum from the entire reconstructed volume is shown in Fig. 4. The mass range up to 80

Table I. Composition (in atomic percent) of the overall reconstructed volume and matrix (highlighted areas, Fig. 2a) for the $\mathrm{Al}-\mathrm{Mg}-\mathrm{Cu}-\mathrm{Si}$ sample aged $\mathbf{1} \mathrm{h}$, as estimated from LEAP data. The nominal composition of the alloy is included for comparison. The balance of the measurements is Al.

\begin{tabular}{lccc} 
Atomic percent & $\mathrm{Mg}$ & $\mathrm{Cu}$ & $\mathrm{Si}$ \\
\hline $\begin{array}{l}\text { Nominal composition } \\
\text { Reconstructed }\end{array}$ & 3.29 & 0.18 & 0.11 \\
$\begin{array}{l}\text { volume } \\
\begin{array}{l}\text { Selected matrix } \\
\text { average }\end{array}\end{array}$ & $2.928 \pm 0.019$ & $0.131 \pm 0.004$ & $0.066 \pm 0.003$ \\
& & &
\end{tabular}




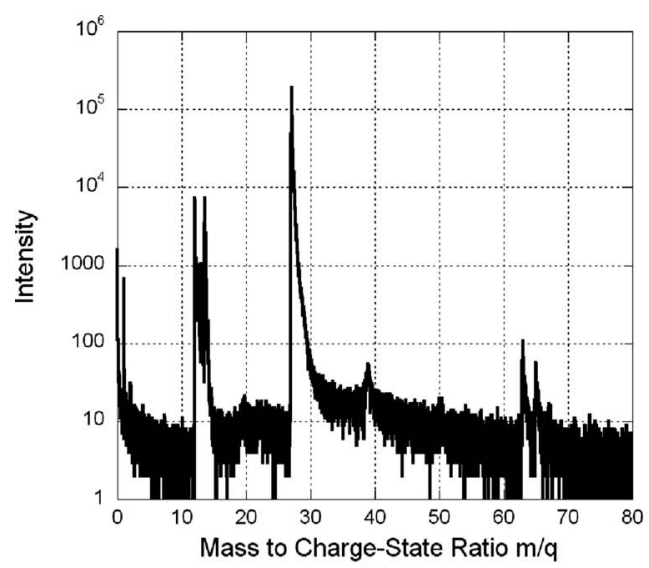

(a)

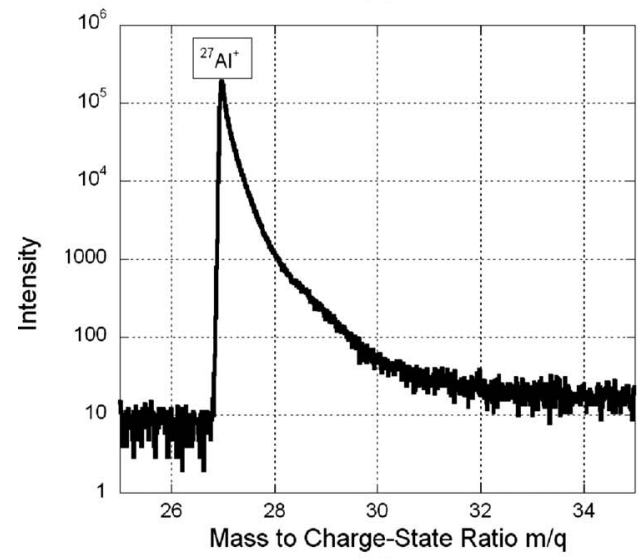

(c)

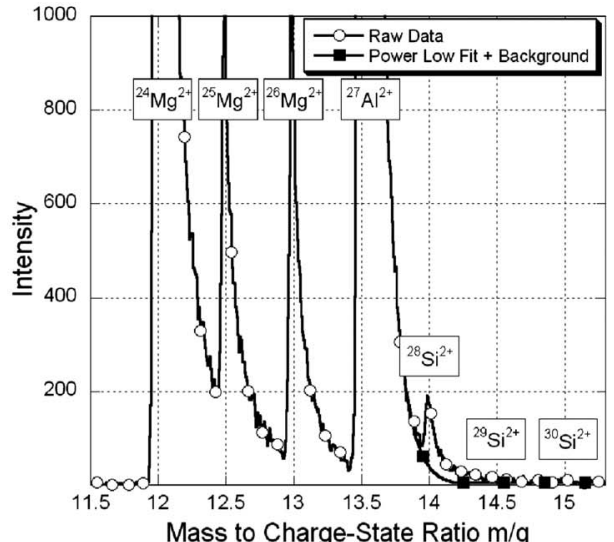

(b)

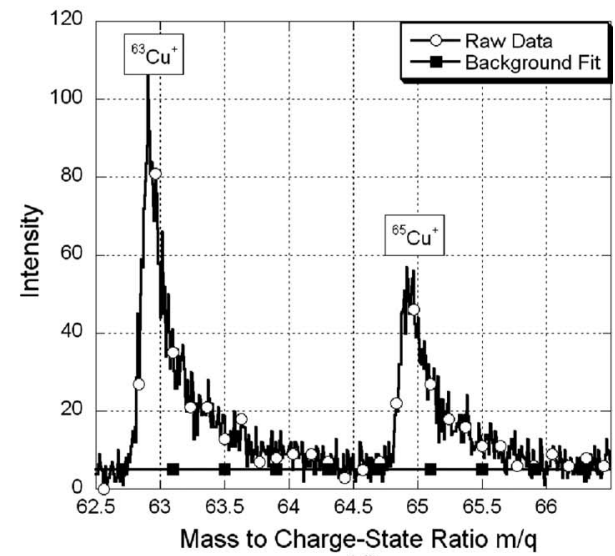

(d) unified atomic mass units (u) is depicted on a logarithmic intensity scale in Fig. 4a, whereas only the mass range from 11.5 to $15 \mathrm{u}$ depicting presence of three isotopes of $\mathrm{Mg}^{2+}$, one of $\mathrm{Al}^{2+}$ and $\mathrm{Si}^{2+}$ is shown in Fig. 4b. The integral intensity of each peak was corrected for the background intensity. For the peaks of $\mathrm{Si}^{2+}$, a further correction was required due to an overlap with the tail of $\mathrm{Al}^{2+}$ peak. The contribution of $\mathrm{Al}^{2+}$ signal to the $\mathrm{Si}^{2+}$ peak intensities was estimated based on a power-law fit to the tail of the $\mathrm{Al}^{2+}$ peak prior to the ${ }^{28} \mathrm{Si}^{2+}$ peak as is shown in Fig. 4b. The true integral intensity of $\mathrm{Si}^{2+}$ could have been calculated based on extrapolation of the $\mathrm{Al}^{2+}$ intensity in the mass-to-charge-state region of the $\mathrm{Si}^{2+}$. Such intensity separation is possible due to the toothlike shape of the field evaporation peaks (sharp rise on the lower end of the mass-to-charge-state spectra and a gradual tail at the higher end of mass-to-charge-state spectra). More information related to the issue of peak separation and deconvolution can be found in the text by Miller and Smith. ${ }^{21}$ Background subtraction and other procedures for quantitative analysis of the atom probe data have also been discussed. ${ }^{22,23}$ In Fig. 4c, the mass-to-charge-state region in the vicinity of the $\mathrm{Al}^{+}$peak is shown. Because of the high intensity of the $\mathrm{Al}^{+}$peak, it is difficult to detect the presence of $\mathrm{Si}^{+}$, which is expected to be located on the shoulder. The detail of the $\mathrm{Cu}^{+}$region is presented in Fig. $4 \mathrm{~d}$.

As is apparent from the discussion above, the determination of the absolute concentration from atom probe data is not straightforward in Si-containing, Al-based alloys due to the proximity of the Al and $\mathrm{Si}$ peaks in the mass spectra. The Si composition is likely to be underestimated. However, the total $\mathrm{Cu}$ and $\mathrm{Mg}$ concentrations in the reconstructed volume can be considered as a representative composition of the matrix of the as-quenched sample, which should be a solid solution $\alpha$ phase. The solute contents are slightly lower than the nominal composition of the alloy due to the formation of some coarse intermetallic phases that were not encountered in this analysis.
The compositional analysis of the eight matrix regions highlighted in Fig. 3a was performed by adding the spectra for each of these volumes together. Because of the low counts in the individual spectra, the compositional analysis introduces uncertainty in the background subtraction and fitting of the tail of $\mathrm{Al}^{2+}$ overlapping with $\mathrm{Si}^{2+}$. The results of the measurement from the combined matrix regions indicate that the average $\mathrm{Mg}, \mathrm{Cu}$, and $\mathrm{Si}$ matrix concentrations are slightly lower than those in the total reconstructed volume, which is in accordance with what is expected from the clustering process.

The relative change in content of the alloying elements in the matrix during aging should provide information that can be used for understanding the corrosion results. The analysis of relative matrix concentration change is presented in Table II, where the values are the averages of the eight independent measurements for each aging time. The percentages for the 1 and $8 \mathrm{~h}$ aged samples represent the amount of each of the alloying atoms still present in the matrix after the aging treatment. By using this procedure for analysis of the matrix regions, the percentage of $\mathrm{Cu}$ in the matrix is found to be lower than that resulting from the prior analysis of the clusters, which determined that 97.7 and $94.9 \%$ of the $\mathrm{Cu}$ atoms were in the matrix after 1 and $8 \mathrm{~h}$ aging, respectively. ${ }^{11}$ This is because regions selected for performing matrix measurements in this work are com-

Table II. Relative changes of the concentration of alloying elements in the $\mathrm{Al}-\mathrm{Mg}-\mathrm{Cu}-\mathrm{Si}$ alloy matrix during aging.

\begin{tabular}{llll} 
& $\mathrm{Mg}$ & $\mathrm{Cu}$ & $\mathrm{Si}$ \\
\hline Reconstructed volume & 100 & 100 & 100 \\
1 h aged, matrix & 97.1 & 91.9 & 77.2 \\
8 h aged, matrix & 86.5 & 66.7 & 40.8
\end{tabular}




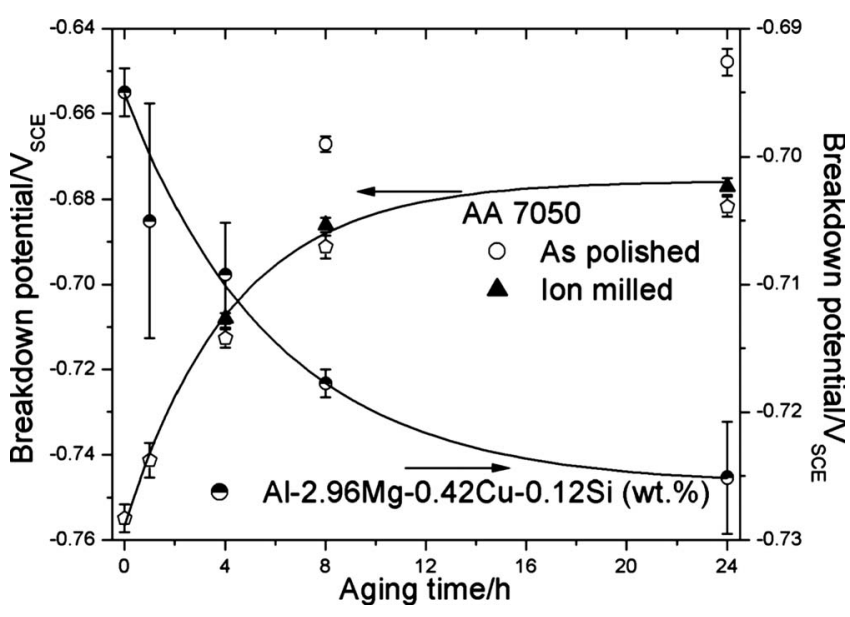

Figure 5. Evolution in the breakdown potentials with aging time for AA7050 aged at $121^{\circ} \mathrm{C}$ and $\mathrm{Al}-\mathrm{Mg}-\mathrm{Cu}-\mathrm{Si}$ aged at $180^{\circ} \mathrm{C}$.

pletely free of clusters, even small clusters of $<10$ atoms, which were considered to be "random clusters" in the previous analysis. ${ }^{11}$

Potentiodynamic polarization curves.- A single breakdown potential was observed for each of the metallurgical states of the Al$\mathrm{Mg}-\mathrm{Cu}-\mathrm{Si}$ alloy studied. The mean and standard deviation are plotted in Fig. 5 as a function of aging time at $180^{\circ} \mathrm{C}$. Two breakdown potentials were observed for the AA7050 samples aged 8 and $24 \mathrm{~h}$, in close agreement with previous results. ${ }^{13,17,18}$ For these samples, each breakdown potential was determined as shown in Fig. 6 for the $24 \mathrm{~h}$ temper. The shape of the curve for this temper is consistent with previous reports for the same alloy; ${ }^{15}$ the small differences in the value of the breakdown potentials can be explained in terms of the lower $\mathrm{pH}$ of the solution and the slightly lower content of copper of the alloy in that study. Because AA7050 alloy naturally ages at room temperature, "as quenched" samples are, in fact, "as quenched and naturally aged" samples. However, for these coupons, the anodic polarization curves measured for increasing naturally aging times from $0.5 \mathrm{~h}$ up to several weeks were quite reproducible.

During polarization experiments of the AA7050 samples aged for 4,8 , and $24 \mathrm{~h}$ at $121^{\circ} \mathrm{C}$, it was observed by eye that several spots

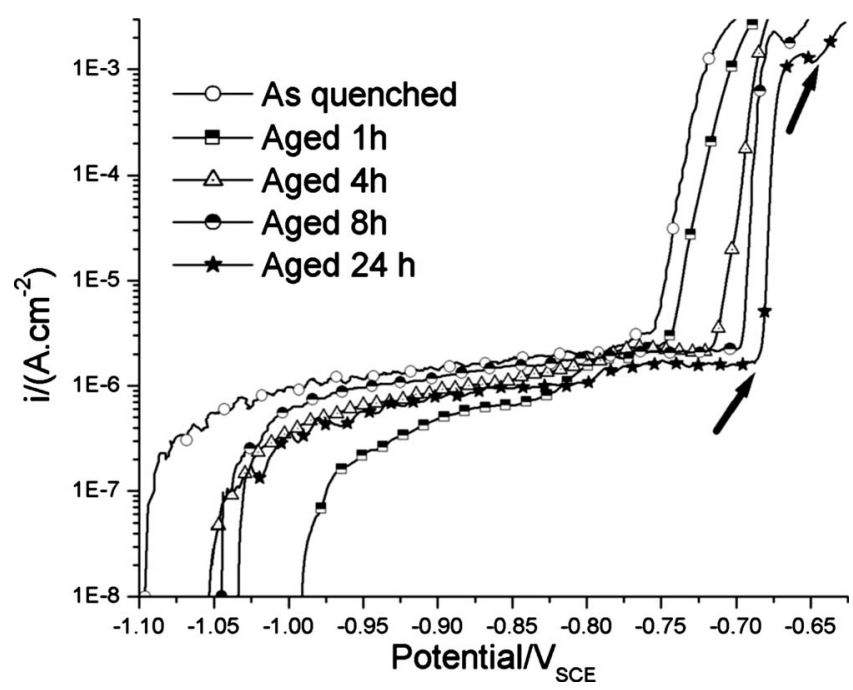

Figure 6. Anodic polarization curves for AA7050 aged different times at $121^{\circ} \mathrm{C}$, in deareated $0.5 \mathrm{M} \mathrm{NaCl}$ at a scan rate of $0.2 \mathrm{mV} / \mathrm{s}$. The arrows point to the first and second breakdown potentials of the sample aged for $24 \mathrm{~h}$

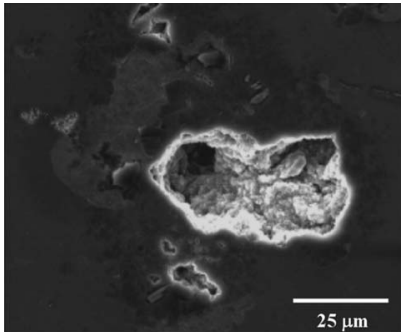

(a)

(c)
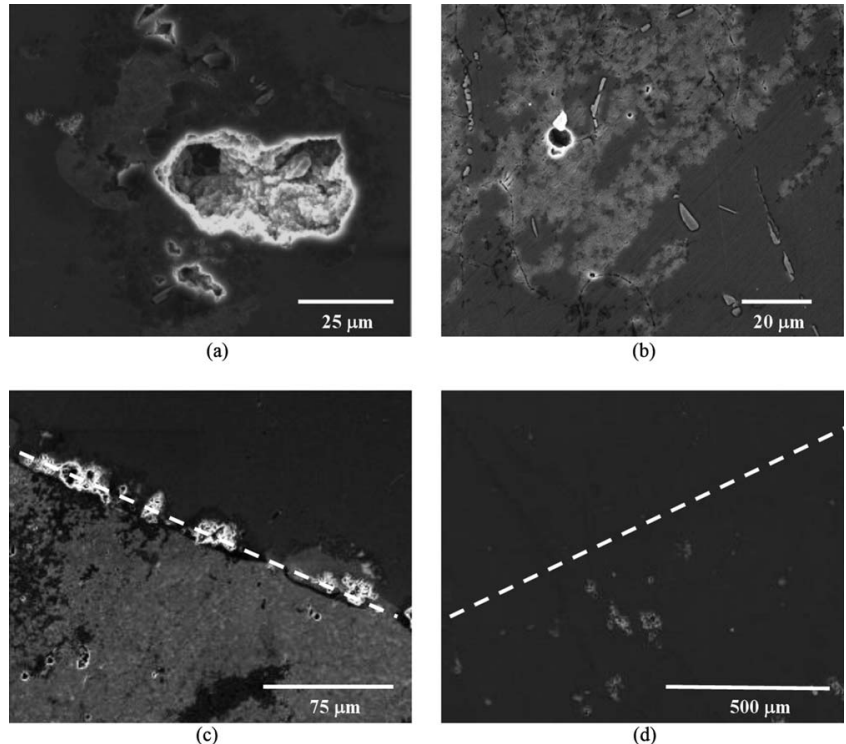

Figure 7. Morphology of the attack observed in the AA7050 alloy, all secondary electron images, (a) as quenched, (b) aged for $4 \mathrm{~h}$, (c) aged for $8 \mathrm{~h}$, and (d) aged for $8 \mathrm{~h}$ and ion milled after polishing. The boundary between the surface exposed and unexposed to the $\mathrm{NaCl}$ solution during the polarization experiment has been schematically drawn in (c) and (d).

appeared on the surface at the first breakdown and spread out as a layer, eventually covering the originally shiny surface. For the other samples studied, pits were observed on a shiny surface with no evidence of layer attack. Recent studies on AA7075 have shown that the first breakdown potential is indeed related to the preferential attack of an active surface layer formed during the polishing process. ${ }^{13,17,18}$ This layer can be removed by means of ion milling, as described above, thus allowing the study of the underlying bulk alloy. Samples aged for 4,8 , and $24 \mathrm{~h}$ exhibited a single breakdown potential after being ion milled, and the values of this potential are shown in Fig. 5.

SEM characterization of as-polarized samples.-Samples were characterized by SEM following polarization to a high potential. As-quenched (Fig. 7a) and $1 \mathrm{~h}$ aged samples of the AA7050 alloy exhibited pits on their surface, which apparently had nucleated randomly. Conversely, the exposed surface of AA7050 samples aged for 4 (Fig. 7b), 8 (Fig. 7c), and $24 \mathrm{~h}$ exhibited a corrosion product with a rippled appearance covering the surface after polarization. Pits can be seen on the surface, apparently having formed underneath the thin, homogeneously corroded surface film. Ion-milled samples of these tempers exhibited only isolated pits on a smooth, shiny surface (Fig. 7d).

For the as-quenched $\mathrm{Al}-\mathrm{Mg}-\mathrm{Cu}-\mathrm{Si}$ alloy, pits with crystallographic shapes were observed in the matrix, as was found for AA7050 in that condition (Fig. 8a). For aged tempers of the Al-Mg$\mathrm{Cu}-\mathrm{Si}$ alloy, intergranular attack was evident as well as pits that appeared to have nucleated on grain boundaries (Fig. 7b).

\section{Discussion}

AA7050.- A double breakdown potential was observed for the AA7050 samples aged for 8 and $24 \mathrm{~h}$, which is consistent with results reported for this and other AA7xxx-T6 alloys (peak aged) in the literature. ${ }^{15}$ Recent studies on AA7075 have provided strong evidence that the first breakdown potential is related to a modified surface layer created during the surface preparation process. ${ }^{13,17,18}$ It has been proposed that the high plastic strain induced during polishing creates a thin surface layer comprised of nanograins with a redistribution of alloying elements, including $\mathrm{Zn}$ and $\mathrm{Mg} .{ }^{13,17,18}$ This surface layer is more susceptible to attack than the underlying bulk 


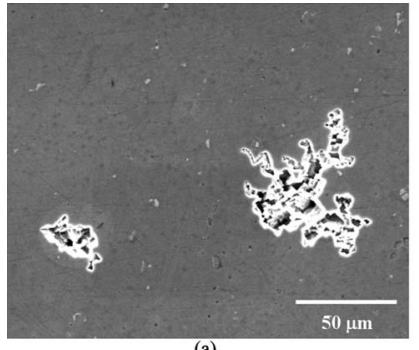

(a)

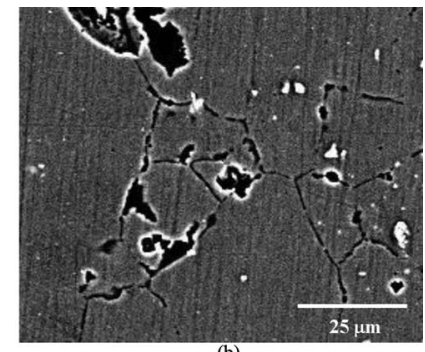

(b)
Figure 8. SEM images of polarized $\mathrm{Al}-\mathrm{Mg}-\mathrm{Cu}-\mathrm{Si}$ alloy: (a) as-quenched, secondary electrons, and (b) sample aged for $1 \mathrm{~h}$, backscattered electrons. Attacked grain boundaries are evident for the $1 \mathrm{~h}$ aged sample.

alloy; thus, at low potentials the dissolution process stops once the layer is consumed and the underlying alloy is not attacked until higher potentials are reached. This phenomenon, which explains the polarization curve showing two breakdown potentials for underaged AA7075, is apparently also valid for the AA7050 aged 8 or $24 \mathrm{~h}$ in this work.

The sample aged for $4 \mathrm{~h}$ exhibited a single breakdown potential but also apparently exhibited layer attack, as evidenced by the corrosion product covering the surface. AA7075 aged for $3 \mathrm{~h}$ at $120^{\circ} \mathrm{C}$ behaved identically. ${ }^{17}$ Video images showed that layer attack occurred in that case. The rate of layer dissolution increased with aging time as a result of the increased hardness and decreased surface layer thickness. ${ }^{18}$ Only one breakdown potential was observed for the $3 \mathrm{~h}$ aged AA7075 because the rate of layer dissolution was so slow that the surface layer was not completely consumed by the time that the potential reached the value for breakdown of the underlying matrix. ${ }^{17} \mathrm{~A}$ video camera was not used to observe the dissolution in this study, but the observation of a corrosion product covering part of the surface for the $4 \mathrm{~h}$ aged sample (Fig. 7b) suggests that layer attack did occur and the same rationale can be used to explain the absence of a second breakdown potential in the polarization curve.

After removal of the susceptible layer on aged AA7050 by ion milling, a single breakdown potential was observed (Fig. 5) and SEM images showed no evidence of thin-film dissolution (Fig. 7d). Although ion milling can create artifacts, such as surface amorphization, radiation damage, and sputter deposition, ${ }^{19}$ the behavior seems to represent that of the underlying metal matrix. The effect of ion milling observed here is similar to that observed previously for underaged samples of AA7075. ${ }^{13}$

Samples exhibiting thin-film dissolution also exhibited crevice corrosion under the edge of the lacquer masking layer (Fig. 7c). As observed for AA7075, the altered surface layer extended below the lacquer, which rendered this structure extremely susceptible to crevice corrosion. Ion-milled samples did not exhibit this form of localized corrosion, and only pits were seen in the as-polarized specimens (Fig. 7d).

The results indicate similar behavior of the AA7050 alloy used in this study and the AA7075 alloy from the previous study. ${ }^{13,17,18}$ However, the work of Sha and Cerezo allows for the determination of AA7050 microstructures that result in the formation of susceptible surface layers. ${ }^{9,14}$ As described above, samples with aging times of $4 \mathrm{~h}$ and longer exhibited surface layer attack. On the basis of Sha and Cerazo's data shown in Fig. 1a, ${ }^{9}$ it can be concluded that surface layer attack in polished AA7050 occurs for microstructures in which $\eta^{\prime}$ is the dominant hardening phase.

The dissolution of $\eta$ and $\eta^{\prime}$ phases intersecting the surface should be expected during the initial moments prior to the polarization of the samples because this phase is active relative to the alloy as a whole, with $E_{\text {corr }}=-1095 \mathrm{mV}_{\mathrm{SCE}}$ in aerated $0.6 \mathrm{M} \mathrm{NaCl}^{3}$ The $\eta$ phase does not form a passive film and dissolves at high rates at potentials higher than its $E_{\text {corr. }}{ }^{24}$ This was verified by observation of a TEM thin foil of AA7075-T651 alloy after immersion in a chloride solution. ${ }^{24}$ Therefore, the susceptibility of $\eta^{\prime}$ itself cannot explain the susceptibility of the surface layer.

Analysis of an AA7075 microstructure by analytical TEM found solute-rich zones lining the nanometer-sized grain boundaries in the surface layers of samples susceptible to surface layer attack. ${ }^{13,17,18}$ It was suggested that the surface layer attack initiated at the active nanograin boundaries followed by nanograin dissolution. Such an analysis was not performed on the surfaces of the AA7050 alloys, but the similar electrochemical behavior suggests that similar structures were formed for the tempers susceptible to layer attack.

Sha and Cerezo found that GPZs were the most numerous for aging times shorter than $4 \mathrm{~h}$ (Fig. 1a), ${ }^{9}$ and it is curious that such microstructures apparently did not form solute-rich zones during polishing. Furthermore, the anodic polarization curves of samples naturally aged for times from $0.5 \mathrm{~h}$ to several weeks (all referred to as "as-quenched samples") did not differ significantly. The hardness increased appreciably as a result of natural aging at room temperature, as described above; thus, the density and distribution of GPZs certainly changed. ${ }^{1}$ Therefore, it can be concluded that AA7050 microstructures with GPZs as the dominant hardening particle do not form the solute-rich bands at the surface during polishing that result in the corrosion susceptibility.

The exact mechanism by which the solute-rich bands form during polishing of microstructures dominated by $\eta^{\prime}$ particles but not for microstructures dominated by GPZs is not known. It was hypothesized that, during polishing, extremely high shear strain results in material rotational flow and mechanical alloying, which eliminates the hardening precipitates. ${ }^{13,17,18}$ The alloying elements returning to the matrix flow in the same direction as the matrix, forming bands. The bands might have been driven to the edge of individual rotating units (i.e., subgrain boundaries), or the bands themselves result in the formation of subgrain boundaries. This process apparently does not occur for GPZs, perhaps because of their coherent nature.

Another interesting aspect of the 3DAP data generated by Sha and Cerezo is the concentration of the matrix phase during the different stages of the aging process. ${ }^{9}$ Although the level of accuracy of these data is debatable (such information is not available even from HRTEM analysis owing to the high density of very small precipitate phases), it can be used to understand the evolution of the breakdown potential for AA7050. The breakdown potential increases with aging time, as shown in Fig. 5, and the solute concentration in the matrix phase decreases during this time as shown in Fig. 1b. Muller and Galvele showed that the pitting potential of binary Al-Zn solid solutions decreases with increasing $\mathrm{Zn}$ content. ${ }^{25}$ Therefore, the increase in breakdown potential during aging of AA7050 might be associated with the depletion of $\mathrm{Zn}$ in the matrix phase. For samples exhibiting thin-film dissolution, the breakdown measured on ionmilled coupons can be taken as representative of the underlying bulk alloy. It should be pointed out the electropolishing used to create the small needles needed for 3DAP would have eliminated any evidence of the surface so that Sha and Cerezo's data represent the bulk material. Furthermore, the matrix $\mathrm{Cu}$ content also decreased during aging, as shown in Fig. 1b, but a decrease in $\mathrm{Cu}$ content should lead to a decrease in breakdown potential, ${ }^{26}$ which was not observed. This supports the notion that the matrix $\mathrm{Zn}$ content controls the matrix breakdown. The steepest increase in pitting potential occurred during the first $8 \mathrm{~h}$ of artificial aging, as shown in Fig. 5, which is coincident with the time of the largest change of the $\mathrm{Zn}$ content in solid solution, as shown in Fig. 1b. Galvele found that little further decrease in pitting potential occurred for increases in $\mathrm{Zn}$ content beyond $3.5 \mathrm{wt} \%{ }^{2 \top}$ A similar finding was observed in a study of artificial crevice electrode samples, in which the repassivation potentials of AlZn binary alloys with 3.96 and 5.86 wt \% were found to be identical. ${ }^{28}$ The results of these two studies of binary AlZn alloys might not be completely applicable to complex commercial alloys. Nevertheless, it may be concluded from the data shown in Fig. 1 and 4 that the steepest descent in the breakdown 
potential occurred during the period of time in which the concentration of $\mathrm{Zn}$ in solid solution decreased from 6 to $4 \mathrm{wt} \%$. This would not have been inferred from the earlier studies on binary alloys, which showed no changes in breakdown potential for variations of $\mathrm{Zn}$ in this range. ${ }^{27,28}$

Al-Mg-Cu-Si alloy.- The Al-Mg-Cu-Si alloy studied in this work did not exhibit layer attack of the form observed for AA7050, and the polarization curves exhibited only a single breakdown. Two breakdown potentials have been observed in polarization curves for an $\mathrm{Al}-\mathrm{Cu}-\mathrm{Mg}$ alloy AA2024-T3, and associated with transient dissolution of $\mathrm{S}$ phase particles. ${ }^{29,30}$ However, such attack was not observed in this work. The $\mathrm{Al}-\mathrm{Mg}-\mathrm{Cu}-\mathrm{Si}$ alloy exhibited pitting corrosion in the as-quenched condition and a combination of pitting and IGC for other tempers, as shown in Fig. 7. Pitting in combination with IGC is common for AA2024-T3. ${ }^{30}$ Kovarik et al. performed extensive investigations of the $\mathrm{Al}-\mathrm{Mg}-\mathrm{Cu}-\mathrm{Si}$ alloy microstructure, ${ }^{10-12}$ but this information on the matrix and hardening particles sheds little insight into the behavior of the grain boundary region. The pitting potential of the $\mathrm{Al}-\mathrm{Mg}-\mathrm{Cu}-\mathrm{Si}$ alloy decreases slightly with aging time, as shown in Fig. 5. It is still unclear whether the presence of GPB zones alone can cause a decrease in pitting potential, due to their nanosize. The attack at the grain boundaries is probably related to the composition of the grain boundary particles and the solute-depleted zone. It is likely that the solute-depleted zones formed during aging and that the $\mathrm{Cu}$ content in their vicinity decreased with aging time. Pits along the grain boundaries are seen in Fig. 8b. However, it is not known whether the pits initiated at the grain boundaries first and then spread to form IGC, or if the IGC initiated first and then developed into pits at certain locations. AA2024-T3 exhibits pitting at lower potentials than IGC. Therefore, in order to obtain information directly relevant to the corrosion processes, it is necessary to perform a detailed composition analysis of the grain boundaries and solute-depleted zones. The present work has nevertheless demonstrated the suitability of ATP for the quantitative determination of matrix composition, even in the presence of extremely small clusters, and thus similar analysis can be performed near grain boundaries as well. Such studies will also be of interest for AA7xxx alloys where the susceptibility to IGC and stress corrosion cracking varies considerably with artificial aging. ${ }^{31}$

\section{Conclusions}

Electrochemical corrosion experiments were performed on samples from two Al alloys for which detailed information of microstructures at the nanoscale level is available. The following can be concluded:

1 Knowledge of the change in matrix composition generated by ATP analysis was useful for rationalizing the change in breakdown potential with tempering time for both AA7050 and the Al-Mg$\mathrm{Cu}-\mathrm{Si}$ alloy. However, the behavior of AA7050 was not what would be expected from changes in the matrix $\mathrm{Zn}$ content based on earlier studies of binary alloys. Alloying interactions and other influences could limit the applicability of binary alloys for understanding complex commercial alloys.

2 The experimental evidence suggested that a susceptible surface layer formed on the AA7050 alloy at certain tempers as the result of polishing, similar to what was previously found for
AA7075. The microstructural studies indicated that these susceptible surface layers on AA7050 only formed when $\eta^{\prime}$ hardening particles were the dominant phase. Structures with GPZs as the dominant hardening phase did not form the susceptible surface layer during polishing.

3 In the present study, the usefulness of the bulk microstructural information was limited by the fact that the corrosion phenomena occurred at surfaces and grain boundaries.

\section{Acknowledgments}

The authors thank A. Cerezo and G. Sha for providing a sample of their alloy. The assistance of Dr. Zhijun Zhao is also appreciated. Research at the Oak Ridge National Laboratory SHaRE User Facility was sponsored by the Scientific User Facilities Division, Office of Basic Energy Sciences, U.S. Department of Energy.

The Ohio State University assisted in meeting the publication costs of this article.

\section{References}

1. I. J. Polmear, Metallurgy of the Light Metals, 3rd ed., Arnold, London (1995).

2. J. E. Hatch, Editor, Aluminum: Properties and Physical Metallurgy, ASM, Metals Park, OH (1984)

3. N. Birbilis and R. G. Buchheit, J. Electrochem. Soc., 152, B140 (2005).

4. M. Büchler, T. Watari, and W. H. Smyrl, Corros. Sci., 42, 1661 (2000)

5. G. S. Frankel, J. Electrochem. Soc., 145, 2198 (1998)

6. C. M. Liao, J. M. Olive, M. Gao, and R. P. Wei, Corrosion (Houston), 54, 451 (1998).

7. J. O. Park, C. H. Paik, Y. H. Huang, and R. C. Alkire, J. Electrochem. Soc., 146, 517 (1999)

8. O. Schneider, G. O. Ilevbare, J. R. Scully, and R. G. Kelly, J. Electrochem. Soc., 151, B465 (2004).

9. G. Sha and A. Cerezo, Acta Mater, 52, 4503 (2004).

10. L. Kovarik, P. I. Gouma, C. Kisielowski, S. A. Court, and M. J. Mills, Acta Mater, 52, 2509 (2004).

11. L. Kovarik, M. K. Miller, S. A. Court, and M. J. Mills, Solid-to-Solid Phase Transformations in Inorganic Materials, Vol. 1, Diffusional Transformations in Solid-to-Solid Phase Transformations in Inorganic Materials, J. M. Howe, D. E. Laughlin, J. K. Lee, U. Dahmen, and W. A. Soffa, Editors, p. 301, TMS, Warrendale, $\mathrm{OH}(2005)$.

12. L. Kovarik, M. K. Miller, S. A. Court, and M. J. Mills, Acta Mater, 54, 173 (2006).

13. Z. Zhao and G. S. Frankel, Corros. Sci., 49, 3064 (2007).

14. G. Sha and A. Cerezo, Surf. Interface Anal., 36, 546 (2004).

15. Q. Meng and G. S. Frankel, J. Electrochem. Soc., 151, B271 (2004).

16. R. S. Huang, C. J. Lin, and H. S. Isaacs, Electrochem. Solid-State Lett., 9, B11 (2006).

17. Z. Zhao and G. S. Frankel, Corros. Sci., 49, 3089 (2007).

18. Z. Zhao and G. S. Frankel, Corrosion (Houston), 63, 613 (2007).

19. D. B. Williams and C. B. Carter, Transmission Electron Microscopy: A Textbook for Materials Science, Springer, New York (1996).

20. P. Ratchev, B. Verlinden, P. De Smet, and P. Van Houtte, Mater. Trans., JIM, 40 , 34 (1999).

21. M. K. Miller and G. D. W. Smith, Atom Probe Microanalysis: Principles and Applications to Materials Problems, Materials Research Society, Pittsburgh (1989).

22. T. F. Kelly and M. K. Miller, Rev. Sci. Instrum., 78, 031101 (2007).

23. M. K. Miller, Atom Probe Tomography: Analysis at the Atomic Level, Kluwar Academic/Plenum Publishing, New York (2000).

24. N. Birbilis, M. K. Cavanaugh, and R. G. Buchheit, ECS Trans., 1(4), 115 (2006)

25. I. L. Muller and J. R. Galvele, Corros. Sci., 17, 995 (1977).

26. I. L. Muller and J. R. Galvele, Corros. Sci., 17, 179 (1977)

27. J. R. Galvele, in Treatise on Materials Science and Technology, J. Scully, Editor, p. 1, Academic Press, London (1983).

28. T. Ramgopal and G. S. Frankel, Corrosion (Houston), 57, 702 (2001).

29. V. Guillaumin and G. Mankowski, Corros. Sci., 41, 421 (1999).

30. W. Zhang and G. S. Frankel, Electrochim. Acta, 48, 1193 (2003).

31. T. Ramgopal, P. I. Gouma, and G. S. Frankel, Corrosion (Houston), 58, 687 (2002). 